\title{
Female tiger Panthera tigris home range size and prey abundance: important metrics for management
}

\author{
Achara Simcharoen, Tommaso Savini, George A. Gale, Saksit Simcharoen \\ Somphot Duangchantrasiri, Somporn Pakpien and James L. D. Smith
}

\begin{abstract}
Tigers Panthera tigris are highly threatened and continue to decline across their entire range. Actions to restore and conserve populations need to be based on science but, in South-east Asia, information on ecology and behaviour of tigers is lacking. This study reports the relationship between the home range size of female tigers and prey abundance, using data from radio-collared tigers in Huai Kha Khaeng Wildlife Sanctuary, Thailand, and published data from other studies. A total of 11 tigers, four males and seven females, were fitted with global positioning system collars, to estimate home ranges using 95 and $100 \%$ minimum convex polygons (MCP). Prey abundance was estimated by faecal accumulation rates. The mean home range size of male tigers was 267 and $294 \mathrm{~km}^{2}$ based on 95 and $100 \% \mathrm{MCPs}$, respectively; the mean female home range size was 70 and $84 \mathrm{~km}^{2}$, respectively. Territories of male and female tigers had little overlap, which indicated both sexes were territorial. Mean densities of the prey species sambar Rusa unicolor, barking deer Muntiacus muntjac and large bovids were $7.5,3.5$ and $3.0 \mathrm{~km}^{-2}$, respectively. When female home range size and prey abundance were compared at six locations in Thailand, and at other sites in India, Nepal, Bangladesh and Russia, a significant negative correlation was found between prey abundance and home range size. Monitoring this relationship can provide managers with metrics for setting conservation goals.
\end{abstract}

Keywords Huai Kha Khaeng Wildlife Sanctuary, Panthera tigris, protected area management, satellite telemetry

\section{Introduction}

The tiger Panthera tigris occurs in a wide range 1 of climates and habitats, from the tropical forests of

Achara Simcharoen ${ }^{*}$ (Corresponding author), Tommaso SAvinI and George A. Gale School of Bioresources and Technology, King Mongkut's University of Technology, Thonburi, Thailand. E-mail simtom@ windowslive.com

Saksit Simcharoen, Somphot Duangchantrasiri and Somporn Pakpien Department of National Parks, Wildlife and Plant Conservation, Thailand

JameS L.D. Sмith Department of Fisheries, Wildlife and Conservation Biology, University of Minnesota, USA

${ }^{*}$ Also at: Department of National Parks, Wildlife and Plant Conservation, Thailand

Received 31 May 2012. Revision requested 13 August 2012.

Accepted 10 October 2012. First published online 13 March 2014.
South Asia to the temperate forests of Far East Russia (Sunquist et al., 1999). However, the species is highly threatened across its entire range by poaching, habitat loss and prey depletion (Kenny et al., 1995; Wikramanayake et al., 1998; Karanth et al., 2004). Its distribution is greatly restricted; populations that are viable, at least in the short term, occur only in Bangladesh, Bhutan, India, Indonesia, Malaysia, Nepal, Russia, and Thailand (Seidensticker, 2010; Walston et al., 2010). The species is extinct in Bali, Java, southern China and central Asia, and populations in other range countries are now severely reduced and at imminent risk of extinction because of their small size (Carroll \& Miquelle, 2006).

In response to these significant declines wildlife managers are attempting a number of strategies, alone or in combination, to increase the number of tigers. Efforts include restoring tiger habitat, re-establishing habitat connectivity, restoring prey populations, reducing poaching of tigers and their prey, and reintroducing animals to the wild (Seidensticker, 2010). All of these management options require an understanding of the relationship of tigers to their prey, and of the influence of ecological variables on both tigers and their prey. Although ecological variables can affect tigers directly, many are likely to have a pronounced influence on the density of the tiger's prey. Current models suggest that, in the absence of heavy poaching, the density of tigers is primarily determined by prey abundance (Karanth et al., 2004; Wegge et al., 2009; Harihar et al., 2009). Documentation of a positive relationship between tiger populations and their prey does not, however, explain the behavioural mechanisms underlying population growth or resilience. As reported for many solitary felids, breeding female tigers in Nepal and Russia occupy defended home ranges (Seidensticker, 1976; Sunquist, 1981; Smith et al., 1987; Goodrich et al., 2010) and individual females have the sole responsibility for raising their young, using prey they acquire within their home range. Although prey abundance varies widely between these two countries, females in both localities are usually able to establish breeding territories large enough to raise young. Because previous studies have demonstrated that female home range size is a function of prey density (Smith et al., 1987; Miquelle et al., 2010) we hypothesize that this relationship holds across the tiger's range and that mean female home range size may be used to calculate local carrying capacity for tigers.

The number of female territories in a population determines that population's recruitment potential 
and ultimately its viability and resilience. Thus, a measurement of the number of breeding female tigers that can exist in a given area (i.e. carrying capacity) is a useful metric for managers. This measurement would be particularly useful if tiger carrying capacity could be approximated by estimating the abundance of prey in a unit of habitat. With this information, managers would be able to predict the response of breeding female home range sizes to changes in prey abundance, as well as to identify if tiger poaching, prey poaching or habitat quality were limiting tiger population size.

We used data from six resident breeding female tigers fitted with global positioning system (GPS) satellite collars in Huai Kha Khaeng Wildlife Sanctuary in western Thailand during 2005-2011 to explore the relationship between female home range size and prey density. We compared our results to those from studies in four other protected areas in which tiger home range size and prey abundance have been previously estimated. The objectives of this study are to (1) estimate home range size and home range overlap of tigers in western Thailand, (2) correlate female tiger home range size and prey density across the tiger's range, and (3) demonstrate the significance of female home range size and prey abundance as two important metrics for reserve managers.

\section{Study area}

The study was conducted in the Huai Kha Khaeng Wildlife Sanctuary (Fig. 1), which, in conjunction with the wildlife sanctuaries Thung Yai East and West, is designated as a UNESCO World Heritage Site. This protected area complex supports the largest tiger population in Thailand (DNP, 2010). In Huai Kha Khaeng Wildlife Sanctuary the estimated tiger density is 3.98 per $100 \mathrm{~km}^{2}$ (Simcharoen et al., 2007). The sanctuary is $2,780 \mathrm{~km}^{2}$, altitudes are $200-1,600 \mathrm{~m}$, annual temperature range is $8-38^{\circ} \mathrm{C}$ and mean annual rainfall is $1,375 \mathrm{~mm}$ (Khao Nang Rum Wildlife Research Station, unpubl. data). Normally the lowest temperatures occur in January and the highest in April. The dry season (November-April) has a mean rainfall of $298 \mathrm{~mm}$ and the wet season (May-October) a mean of $1,088 \mathrm{~mm}$. The area has four main vegetation types, the occurrence of which depends on rainfall patterns and edaphic conditions: mixed deciduous forest (48\%), dry evergreen forest $(25 \%)$, hill evergreen forest (13\%) and dry deciduous dipterocarp forest ( $7 \%$; WEFCOM, 2004).

In addition to the tiger, other carnivores in the sanctuary include the leopard Panthera pardus, clouded leopard Neofelis nebulosa, marbled cat Pardofelis marmorata, leopard cat Prionailurus bengalensis, Asiatic jackal Canis aureus, wild dog Cuon alpinus, Asiatic black bear Ursus thibetanus and sun bear Helarctos malayanus. Four major

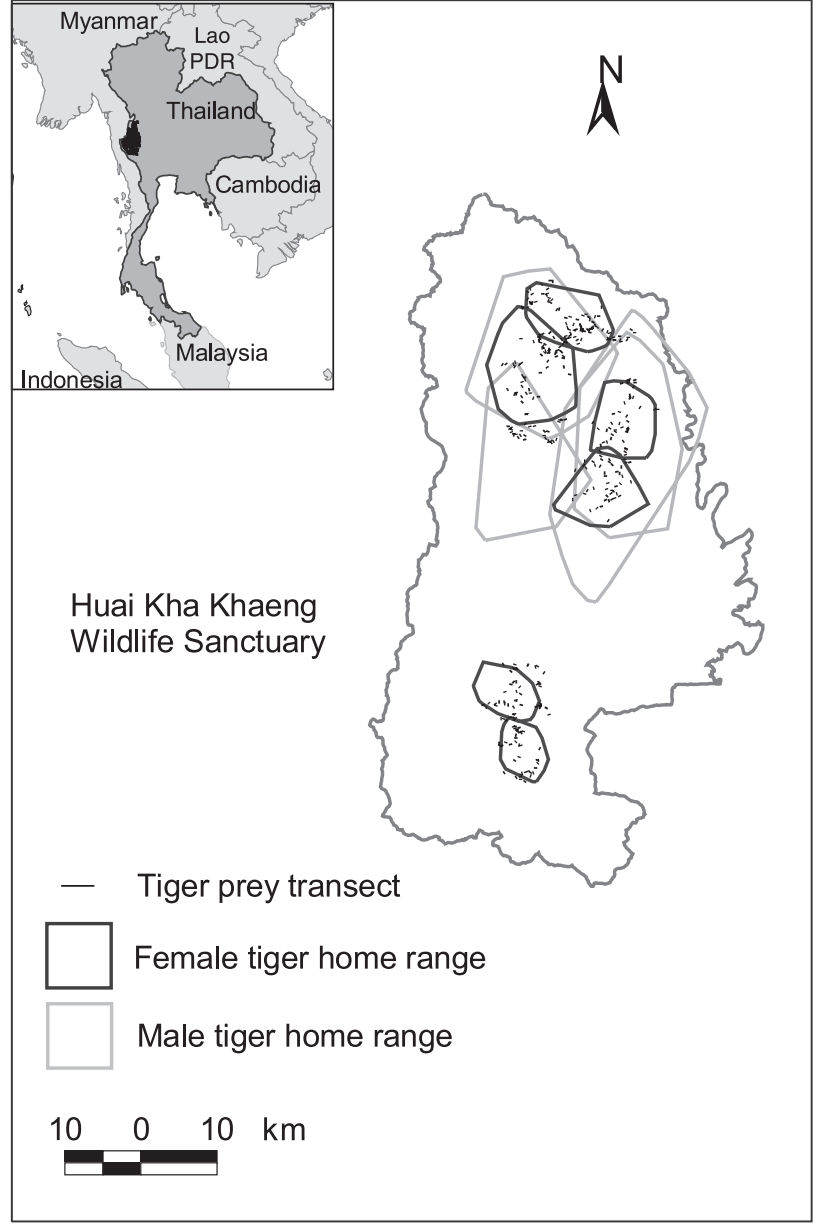

FIG. 1 Huai Kha Khaeng Wildlife Sanctuary, with the prey survey transects in six female tiger home ranges. The dark-shaded area on the inset indicates the location of the main map in Thailand, on the border with Myanmar.

tiger prey species occur in high numbers in the area: banteng Bos javanicus, gaur Bos gaurus, sambar Rusa unicolor and wild boar Sus scrofa (Srikosamatara, 1993).

\section{Methods}

\section{Capture and radio collaring}

During June 2005-August 2011 we captured tigers in parts of Huai Kha Khaeng Wildlife Sanctuary that represent the range of habitat types and topographic features in the Sanctuary. Healthy live domestic cows were placed along trails where repeated recent tiger scent marks occurred. When a cow was killed three or four leg-hold snares were set near the cow to capture the tiger when it returned to feed the next night. The snares were designed by P. Pratumratanatarn, an experienced technician with the Department of National Parks, Wildlife and Plant Conservation. Captured tigers were anaesthetized with a mixture of tiletamine HCL and zolazepam HCL (Zoletil; Virbac Laboratories, Carros, France) at a dose of $4 \mathrm{mg} \mathrm{kg}^{-1}$ 
(Kreeger \& Arnemo, 2007). At the time of capture we recorded sex, age and reproductive status. The age of each tiger was estimated from tooth eruption, tooth wear and staining. Reproductive status of females was classified as nulliparous if nipples were pink; dark nipples indicated a female had produced young. Animal handling and immobilization were undertaken in accordance with the University of Minnesota IACUC protocol o906A67489.

Breeding tigers were fitted with one of three radio collar models: Advanced Telemetry Systems (ATS) GPS collar model G200o (Isante, Minnesota, USA), Telonics Argos Terrestrial Transmitter (Mesa, Arizona, USA), or Vectronic Aerospace GmbH GPS Plus (Berlin, Germany). The ATS collars were programmed to acquire locations every 2 hours. Telonics and Vectronic collars were programmed to acquire locations every hour. All radio collars were released with drop-off mechanisms. ATS and Telonics models had to be recovered to download data but the Vectronic model transmitted data via Iridium satellites and the data were available from the Vectronic website. Output of all collars included date, time, latitude, longitude, altitude and fix status. We used location data from both two- and three-dimensional fixes.

\section{Home range size and overlap}

We used 95 and 100\% minimum convex polygons (MCP) to estimate home range size of tigers (Jennrich \& Turner, 1969). Because the $100 \%$ MCP can be influenced by outliers, the $95 \% \mathrm{MCP}$ is often preferred, to avoid inflation of the estimate (Harris et al., 1990; White \& Garrott, 1990). The MCP is also the most widely used home range estimator (Harris et al., 1990), which facilitates comparisons with other studies. To determine the number of locations needed to obtain stable home range areas we conducted a bootstrap simulation in which home range size was estimated from randomly selected locations. We began with 50 locations and increased the sample size by 50 until all radio locations were included in the calculations. We considered the home range established when the number of days or the number of fixes reached an asymptote (Harris et al., 1990). The kernel method, in contrast to the MCP, is best as an estimator of the probability of use within a home range and thus can address questions related to third-order selection (sensu Johnson, 1980). But the kernel method can be problematic for estimating home range size, especially as the number of locations increases with the use of GPS collars (Downs \& Horner, 2008). Kernel estimates are particularly inflated when there is a large number of locations along a 'hard' boundary, which is often the case for animals, such as tigers, that defend home ranges (Downs \& Horner, 2008). Therefore, we believe that the 95\% MCP is a suitable estimator for testing our hypothesis that prey density is an important factor determining the size of tiger home ranges. However, we include 100\% MCP estimates here also to facilitate comparison with other studies.

To determine if a female home range was used exclusively by a single female to obtain food for herself and her young, we defined neighbouring females as those that had adjacent (with insufficient space or evidence for there to be another female living in between) and potentially overlapping home ranges during the same time period. Overlaps were based on the frequency a female used the same geographical locations as her female neighbours (at least once per month). As we did not have data for all female home ranges surrounding our study females we could only estimate the minimum percentage overlap (100\% MCPs), defined here as $H R_{i j}=A_{i j} / A_{i}$, where $H R_{i j}$ is the proportion of individual $i$ 's home range that is overlapped by individual $j$ 's home range, $A_{i}$ is the area of individual $i$ s home range and $A_{i j}$ is the area of overlap between the two individuals' home ranges (Kernohan et al., 2001). The home range sizes and degree of overlap of radio collared tigers were calculated using the ArcView v. 3.3 (ESRI, Redlands, USA) extension package Home Range (Rodgers \& Carr, 1998).

\section{Prey abundance}

We estimated prey abundance during the dry season (December-April) for 2009-2011. In addition, prey abundance in the entire Sanctuary has been monitored since 2006 as part of sanctuary management; these data suggested that prey density was approximately constant during 2006-2011 (Wildlife Conservation Society, unpubl. data).

We used faecal accumulation rate techniques (Bailey \& Putman, 1981) to estimate prey abundance in the Sanctuary. Four c. $100 \mathrm{~km}^{2}$ areas that encompassed the six female tiger home ranges were selected to represent the range of habitat types and topographic features in the Sanctuary. Two sites were in the central valley of the Sanctuary along the lower and upper portions of the Huai Kha Khaeng River. The lower site was characterized by mixed deciduous forest. The upper site was a combination of mixed deciduous and dry evergreen forest and the habitat was more rugged than at the lower site. A third site, near the Khao Nang Rum Wildlife Research Station, was a drier area away from the Huai Kha Khaeng River. It was composed of a combination of dry dipterocarp and mixed deciduous habitat. The fourth site was in the northern part of the Sanctuary, and also away from the Huai Kha Khaeng River. It was characterized by mixed deciduous and dry evergreen habitat in rugged terrain.

A total of 90 square line transects, $200 \times 200 \mathrm{~m}$, were randomly located in each of the four sites (Fig. 1) to survey gaur and banteng, as dung of these species is relatively 
rare. In addition, 40 circular plots of $20 \mathrm{~m}^{2}$ were placed $20 \mathrm{~m}$ apart on each of these transects, to sample the more common ungulates (sambar, barking deer Muntiacus muntjac and wild boar). All ungulate pellet groups were counted and removed from all transects and circular plots. Following removal, new faecal accumulation was measured for a period of 30 days (over this time period no entire pellet groups were lost to decomposition or other natural processes during the dry season). A pellet group consisted of $>_{15}$ pellets. Pellet groups that overlapped were distinguished by size and colour, which became lighter as pellets aged.

We searched for gaur and banteng dung piles up to $2 \mathrm{~m}$ either side of the transects. Observed piles were counted and marked, and the perpendicular distance from the transect was measured. We could not distinguish gaur and banteng dung and therefore combined the data, as large bovid'. To determine absolute abundance of prey species we used published defecation rates of large bovids (9.5 dung piles per day) and barking deer (7.5 pellet groups per day; Srikosamatara, 1993; Sukmasuang, 2001). For sambar we recorded the defecation rate of a group of six animals of mixed sex and age (one male, two females and three young) at Khao Pratapchang Wildlife Breeding Centre. To control for possible seasonal differences in defecation rate, observations at the Centre were made in the same season as the field study. During a 5 -day period deer grazed undisturbed; in a second 5-day period deer were stimulated so that they were more active than normal. Deer were fed a diet of natural browse that was cut near the breeding centre, to provide a diet similar in species and cellulose composition to their natural diet. The mean number of pellet groups per individual per day was $9.5 \pm \mathrm{SD} 1.41(\mathrm{n}=6)$. We calculated deer and barking deer density as $D=(P / A) /(D f D s)$, where $P=$ the number of pellet groups found on the second visit, $A=$ the total sample area $\left(\mathrm{km}^{2}\right), D f=$ the defecation rate and $D s=$ the number of days between the two visits. Distance v. 5.o (Thomas et al., 2006) was used to estimate the density of dung, which was then used to estimate large bovid abundance. Data were right truncated at $1.2 \mathrm{~m}$ and grouped into $0.2 \mathrm{~m}$ intervals to improve model fit. Uniform and half-normal models for the detection function were fitted against the data, using cosine adjustments (Buckland et al., 2001). The best model selection and adjustment terms were based on Akaike's Information Criterion (AIC; Akaike, 1974). We calculated large bovid density $B D=D d /(D f D s)$, where $D d=$ bovid dung density, $D f=$ defecation rate of bovids, and $D s=$ number of days between the two visits.

\section{Home range size and prey abundance}

We estimated prey biomass in six resident female tiger home ranges in the Sanctuary to determine the correlation between female home range size and prey abundance at the local level. Across the tiger's range we reviewed information on tiger home range size and prey abundance from five studies in Nepal, India, Bangladesh and Russia that had used radio telemetry to estimate home range size. In all studies home range size was estimated by either the 95 or $100 \%$ MCP. Using data from earlier studies we estimated prey biomass for each site as the product of prey density and mean body weight (Dhungel \& O'Gara, 1991; Karanth \& Sunquist, 1992). We then used simple linear regression to predict home range size in relation to prey abundance at the local level and Spearman's rank correlation to determine if the same relationship holds at a range-wide level (our results from Huai Kha Khaeng Wildlife Sanctuary combined with published data). Probabilities $<0.05$ were considered significant.

\section{Results}

\section{Home range size and overlap}

A total of 11 tigers, seven resident breeding females and four resident breeding males, were fitted with GPS collars. One female and one male were collared twice, at separate times, and home range estimates were made for each period for each individual as size and shape of home ranges changed over time. The mean number of days used for home range analysis was $152 \pm S D 72$ days (range $77-358$ days). The mean time to reach an asymptote in home range size was $77 \pm$ SD 35 days and the mean number of fixes to reach an asymptote was $418 \pm$ SD 160 locations. The mean number of locations used to estimate home range was 1,502 \pm SD 1,215. Mean home range $(95 \% \mathrm{MCP})$ of the resident females $(\mathrm{n}=8)$ was $70.2 \pm \mathrm{SD} 33.2 \mathrm{~km}^{2}$ and that of the resident males was $267.6 \pm$ SD $92.4 \mathrm{~km}^{2}(\mathrm{n}=5$; Table 1$)$. Mean home range estimated with the $100 \% \mathrm{MCP}$ was $84.2 \pm \mathrm{SD} 40.8 \mathrm{~km}^{2}$ $(\mathrm{n}=8)$ and $294.1 \pm \operatorname{SD} 100.3 \mathrm{~km}^{2}(\mathrm{n}=5)$ for the resident males and females, respectively (Table 1 ). The ratio of male to female tiger home range size was $3.8: 1$.

Home range overlap was examined from three pairs of adjacent females and one pair of adjacent males. Mean overlap was $4.5 \pm \mathrm{SD}_{3} \%$ for the females and $18 \%$ for the males. We used five female home ranges within three male home ranges to examine overlap between male home ranges and sympatric female home ranges. Male home ranges overlapped nearly the entire sympatric home range of the females ( $90 \pm$ SD $15 \%, \mathrm{n}=5)$.

\section{Prey abundance}

Mean densities of sambar and barking deer were $7.5 \pm \mathrm{SD} 6$ and $3.5 \pm \mathrm{SD} 2.6 \mathrm{~km}^{-2}$ over the four sites. Our sample of wild boar dung $(n=77)$ was insufficient for 
TABLE 1 Estimates, using 95 and 100\% minimum convex polygons (MCP), of the home range size of 11 individual collared tigers (one male and one female were collared twice) in Huai Kha Khaeng Wildlife Sanctuary, Thailand (Fig. 1).

\begin{tabular}{|c|c|c|c|c|}
\hline \multirow[b]{2}{*}{ Tiger } & \multirow[b]{2}{*}{ Data collection period } & \multirow[b]{2}{*}{ No. of fixes } & \multicolumn{2}{|c|}{ Home range size $\left(\mathrm{km}^{2}\right)$} \\
\hline & & & $95 \% \mathrm{MCP}$ & $100 \% \mathrm{MCP}$ \\
\hline Male 1 & May-Aug. 2005 & 542 & 246.1 & 291.2 \\
\hline Male 2 & Feb.-Oct. 2008 & 333 & 174.8 & 197.0 \\
\hline Male 3 & Apr.-June 2009 & 1,235 & 281.2 & 289.3 \\
\hline Male 4 & Apr.-July 2009 & 1,899 & 218.5 & 234.0 \\
\hline Male 5 & June-Nov. 2011 & 2,659 & 417.5 & 459.0 \\
\hline Female 1 & Feb.-July 2005 & 470 & 57.0 & 69.84 \\
\hline Female 2 & Jan.-Dec. 2005 & 529 & 52.9 & 78.2 \\
\hline Female 3 & Feb. 2007-Feb. 2008 & 738 & 122.3 & 155.9 \\
\hline Female 4 & Feb.-June 2010 & 1,537 & 117.1 & 133.5 \\
\hline Female 5 & Mar.-July 2010 & 2,126 & 61.6 & 75.3 \\
\hline Female 6 & Dec. 2009-July 2010 & 4,585 & 31.0 & 36.6 \\
\hline Female 7 & Aug.-Nov. 2010 & 608 & 75.6 & 78.3 \\
\hline Female 8 & May.-Nov. 2011 & 2,274 & 44.1 & 46.0 \\
\hline
\end{tabular}

precise density estimation and therefore we used the density of wild boar in the Sanctuary $\left(2.4 \pm\right.$ SD $\left.0.05 \mathrm{~km}^{-2}\right)$ estimated by Sukmasuang (2001). To estimate large bovid density by distance sampling we first tested models of dung observability based on distance from the transects. During the surveys 105 bovid dung piles were detected. The best model for observability based on the lowest AIC score was a uniform cosine distribution. The bovid dung density was estimated to be $860 \pm S D 126 \mathrm{~km}^{-2}$ and, from this, bovid density was estimated to be $3.0 \pm \mathrm{SD} 0.4 \mathrm{~km}^{-2}$.

\section{Home range size and prey abundance}

The simple linear regression indicated there was a significant negative correlation between size of female home range and prey biomass $\left(\mathrm{r}^{2}=0.70, \mathrm{P}<0.05, \mathrm{n}=6\right)$. This relationship appeared to be log-linear as a $\log$ transformation of the home range size gave a better fit $\left(\mathrm{r}^{2}=0.85, \mathrm{P}<0.05, \mathrm{n}=6\right.$; Fig. 2$)$. At a regional scale (Table 2) we found the same relationship (Spearman $\mathrm{r}_{\mathrm{s}}=0.88, \mathrm{P}<0.005, \mathrm{n}=6$ ).

\section{Discussion}

Our results support the hypothesis that variation in the home range size of female tigers is partially explained by variation in prey density. The relationship appears to be log-linear, probably reflecting the biological upper and lower limits of home range sizes within the study area. This relationship indicates that home range size of female tigers is relatively constant when prey biomass is $>5,000 \mathrm{~kg} \mathrm{~km}^{-2}$, indicating minimum home ranges of $10-20 \mathrm{~km}^{2}$ (Fig. 2). In carnivores a direct relationship between higher prey abundance and smaller home range sizes has been reported in many species, including bobcat Felis rufus

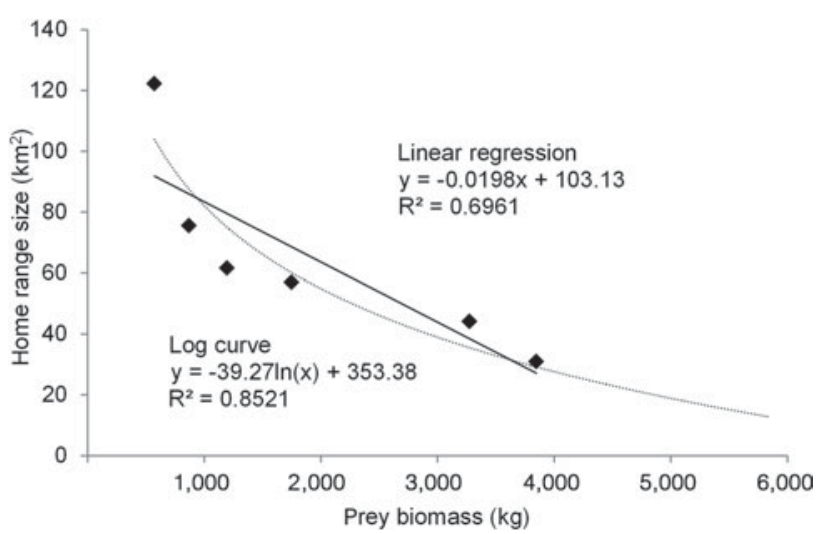

FIG. 2 Correlation between the home range size of six female tigers and prey biomass in Huai Kha Khaeng Wildlife Sanctuary (Fig. 1). The linear regression indicates that the home range size of female tigers is significantly correlated $(\mathrm{P}<0.05)$ with prey density.

(Litvaitis et al., 1986) and Canadian lynx Lynx canadensis (Ward \& Krebs, 1985). Schaller (1972), Orsdol et al. (1985) and Hayward et al. (2007) also demonstrated this relationship for large African felids.

To test our hypothesis that a female's home range should be large enough to support the prey requirements for a female and her cubs from birth until they disperse at c. 18 months (Smith et al., 1987), we needed a home range estimator that defined the area in which a female acquires food. We also needed to test the degree to which females have exclusive home ranges. Choice of home range estimators depends on the question being addressed (Kie et al., 2010) and therefore we calculated home range as both the 95 and $100 \%$ MCPs (Smith et al., 1987; Chundawat et al., 1999; Karanth \& Sunquist, 2000; Goodrich et al., 2010; Barlow et al., 2011). For female tigers home ranges are not only related to prey abundance but are exclusively used by an individual female. 


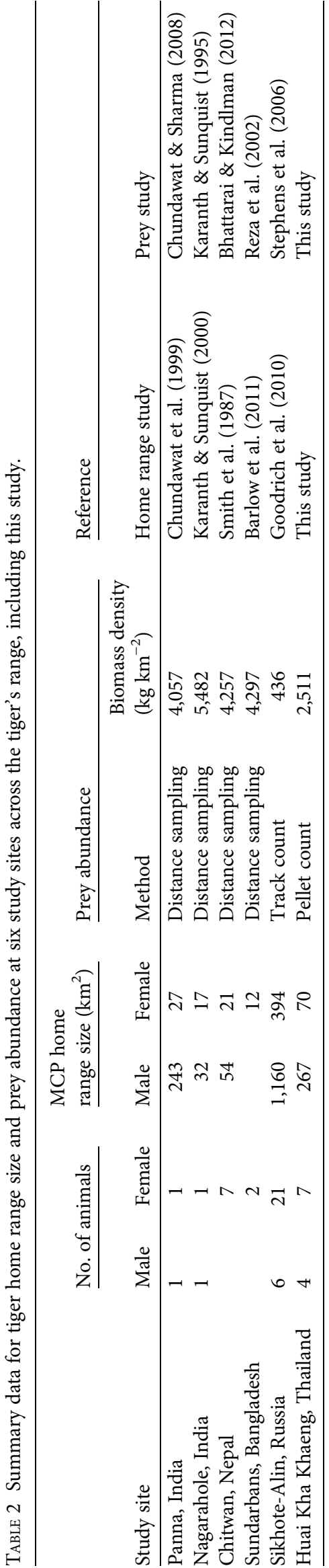

Tigers in Russia and Nepal exhibit territorial behaviour as a strategy to ensure access to adequate prey to raise their young to dispersal age (Smith et al., 1987, Goodrich et al., 2010). This behaviour is also common in other solitary female carnivores (Sandell, 1989). We did not document aggressive behaviour among females as an indicator of territorial behaviour but we did find that territorial overlap among females is small. For example, three pairs of adjacent females had an overlap of only $4 \%$, which is similar to estimates from Nepal, where the overlap of females was 3.5-7\% (Smith et al., 1987), and Russia, where female tigers had a mean overlap of $9 \%$ (Goodrich et al., 2010).

Factors other than prey, such as poaching of tigers, may reduce competition among females and result in home ranges larger than needed to supply food resources. These conditions may confound the negative relationship between female tiger home range size and prey abundance. When density of tigers was low in Nepal during periods when habitat was recovering from human disturbance, tiger home ranges were larger than needed and this allowed females to make room for their dispersing daughters (Smith et al., 1987).

In contrast it is widely reported that home range size for male solitary carnivores is not influenced by food requirements, as males attempt to hold territories that encompass as many females as possible (Sandell, 1989). The home range size, and thus the number of females that a male may mate with, is constrained by the energy and time requirements expended visiting females to track their reproductive status, and patrolling boundaries to discourage intruding males that may kill cubs (Sandell, 1989). Mean male home range size in Huai Kha Khaeng Wildlife Sanctuary was 3.8 times larger than the mean female home range. This ratio is similar to the ratio of home range size between male and female tigers in Russia and Nepal (Smith et al., 1987; Goodrich et al., 2010).

Although our sample size for the correlation between home range and prey is small, it is currently the best information available. Tracking the relationship between female home range size and prey abundance is a useful tool for managers because it provides them with a metric for setting management goals. Hayward et al. (2007) suggested that the next step in refining the relationship between female home range size and prey abundance is to analyse the ecological factors that predict prey abundance. Detailed information on female home range size, prey abundance and the ecological factors that determine prey abundance will allow managers to develop appropriate management actions. For example, when female home range sizes are larger than needed to supply adequate prey for breeding females to raise their young, managers should investigate the possibility that tigers are being poached. Alternatively, when prey abundance is below the potential carrying capacity predicted by environmental variables, managers 
should examine whether prey are being poached. In contrast, if the mean size of home ranges is at the minimum size given the prey density, then the only management option to increase the viability of the tiger population is to enlarge the area available. If in the next few years female home range size increases in Huai Kha Khaeng Wildlife Sanctuary, managers should investigate if it is because of declining prey abundance or an increase in tiger poaching. Faced with continued threats to tigers, conservationists have focused on strategies that emphasize conserving source populations (Walston et al., 2010) or entire landscapes (Sanderson, 2010). These efforts provide important guidelines, and strategic conservation planning is essential. Poaching, reduced carrying capacity and the loss of the land area available to tigers have been identified as the key threats to the species (Kenny et al., 1995; Chapron et al., 2008; Seidensticker, 2010). Managers can use the relationship between female home range size and prey abundance, along with long-term camera-trap monitoring of tiger populations, to examine the threats specific to tigers in each protected area.

\section{Acknowledgements}

We acknowledge the Department of National Parks, Wildlife and Plant Conservation, and especially Chatchawan Pitdumkam and Theerapat Prayurasiddhi, for supporting this work. We also appreciate the help provided by the former chiefs of Huai Kha Khaeng Wildlife Sanctuary, Sunthorn Chaiwatana and Apicha Yusombune. Funding was provided by PTTEP (Thailand), the U.S. Fish and Wildlife Service, The Royal Golden Jubilee $\mathrm{PhD}$ Programme (Thailand) and the Biodiversity Research and Training Programme (Thailand). We are also grateful to research assistants Onsa Norasarn, Thavorn Thadvichit, Kerkpol Wongchu, Boonyang Srichan, Yingbune Chongsomchai, Kerati Phetong, Nattakarn Pengmark, Namkang Saelee and Parinyakorn Worawan for their help with the capture of tigers and field data collection. We are particularly grateful to Francesca J. Cuthbert, Erin Roche, Anak Pattanavibool, Vijak Chimchom, John Fieberg and Adam Barlow for their comments the article and for suggestions regarding data analysis.

\section{References}

Aкатке, H. (1974) A new look at the statistical model identification. IEEE Transactions on Automatic Control, 19, 716-723.

Bailey, R.E. \& PUtman, R.J. (1981) Estimation of fallow deer (Dama dama) populations from faecal accumulation. Journal of Applied Ecology, 18, 697-702.

Barlow, A.C.D., Smith, J.L.D., Ahmad, I.U., Hossain, A.N.M., Rahman, M. \& Howlader, A. (2011) Female tiger Panthera tigris home range size in the Bangladesh Sundarbans: the value of this mangrove ecosystem for the species' conservation. Oryx, $45,125-128$.

Bhattarai, B.P. \& Kindlmann, P. (2012) Habitat heterogeneity as the key determinant of the abundance and habitat preference of prey species of tiger in the Chitwan National Park, Nepal. Acta Theriologica, 57, 89-97.

Buckland, S.T., Anderson, D.R., Burnham, K.P., LaAke, J.L., Borchers, D.L. \& Thomas, L. (2001) Introduction to Distance Sampling: Estimating Abundance of Biological Populations. Oxford University Press, Oxford, UK.

Carroll, C. \& Miquelle, D.G. (2006) Spatial viability analysis of Amur tiger Panthera tigris altaica in the Russian Far East: the role of protected areas and landscape matrix in population persistence. Journal of Applied Ecology, 43, 1056-1068.

Chapron, G., Miquelle, D.G., Lambert, A., Goodrich, J.M., Legendre, S. \& Clobert, J. (2008) The impact on tigers of poaching versus prey depletion. Journal of Applied Ecology, $45,1667-1674$.

Chundawat, R.S., Gogate, N. \& Johnsingh, A.J.T. (1999) Tigers in Panna: preliminary results from an Indian tropical dry forest. In Riding the Tiger: Tiger Conservation in Human-Dominated Landscapes (eds J. Seidensticker, S. Christie \& P. Jackson), pp. 123-129. Cambridge University Press, Cambridge, UK.

Chundawat, R.S. \& Sharma, K. (2008) Tiger prey in a tropical dry forest: an assessment of abundance and of biomass estimation derived from distance sampling. Journal of the Bombay Natural History Society, 105, 64-72.

Dhungel, S.K. \& O'Gara, B.W. (1991) Ecology of the hog deer in Royal Chitwan National Park, Nepal. Wildlife Monographs, 119, 3-40.

DNP (2010) Thailand Tiger Action Plan 2010-2022. Department of National Parks, Wildlife and Plant Conservation, Bangkok, Thailand.

Downs, J.A. \& Horner, M.W. (2008) Effects of point pattern shape on home-range estimates. Journal of Wildlife Management, 72, $1813-1818$

Goodrich, J.M., Miquelle, D.G., Smirnov, E.N., Kerley, L.L., Quigley, H.B. \& Hornocker, M.G. (2010) Spatial structure of Amur (Siberian) tigers (Panthera tigris altaica) on Sikhote-alin Biosphere Zapovednik, Russia. Journal of Mammalogy, 91, 737-748.

Harihar, A., Pandav, B. \& Gopal, S.P. (2009) Responses of tiger (Panthera tigris) and their prey to removal of anthropogenic influences in Rajaji National Park, India. European Journal of Wildlife Research, 55, 97-105.

Harris, S., Cresswell, W.J., Forde, P.G., Trewhella, W.J., Woodlard, T. \& Wray, S. (1990) Home-range analysis using radio-tracking data-a review of problems and techniques particularly as applied to the study of mammals. Mammal Review, 20, 97-123.

Hayward, M.W., O’Brien, J. \& Kerley, G.I.H. (2007) Carrying capacity of large African predators: predictions and tests. Biological Conservation, 139, 219-229.

Jennrich, R.I. \& TURner, F.B. (1969) Measurement of non-circular home range. Journal of Theoretical Biology, 22, 227-237.

Johnson, D.H. 1980. The comparison of usage and availability measurements for evaluating resource preference. Ecology, 61, 65-71.

Karanth, K.U., Nichols, J.D., Kumar, N.S., Link, W.A. \& Hines, J. E. (2004) Tigers and their prey: predicting carnivore densities from prey abundance. Proceedings of the National Academy of Sciences of the United States of America, 101, 4854-4858.

Karanth, K.U. \& Sunquist, M.E. (1992) Population structure, density and biomass of large herbivores in the tropical forests of Nagarahole, India. Journal of Tropical Ecology, 8, 21-35. 
Karanth, K.U. \& Sunquist, M.E. (1995) Prey selection by tiger, leopard and dhole in tropical forests. Journal of Animal Ecology, $64,439-450$.

Karanth, K.U. \& Sunquist, M.E. (2000) Behavioural correlates of predation by tiger (Panthera tigris), leopard (Panthera pardus) and dhole (Cuon alpinus) in Nagarahole, India. Journal of Zoology, 250, 255-265.

Kenny, J.S., Smith, J.L.D., Starfield, A.M. \& McDougal, C. (1995) The long-term effects of tiger poaching on population viability. Conservation Biology, 9, 1127-1133.

Kernohan, B.J., Gitzen, R.A. \& Millspaugh, J.J. (2001) Analysis of animal space use and movements. In Radio Tracking and Animal Populations (eds J.J. Millspaugh \& J.M. Marzluff), pp 125-166. Academic Press, San Diego, USA.

Kie, J.G., Matthiopoulos, J., Fieberg, J., Powell, R.A., Cagnacci, F., Mitchell, M.S. et al. (2010) The home-range concept: are traditional estimators still relevant with modern telemetry technology? Philosophical Transactions of the Royal Society B, 365, 2221-2231.

Kreeger, T.J. \& Arnemo, J.M. (2007) Handbook of Wildlife Chemical Immobilization. Sunquest Print, China.

Litvaitis, J.A., Sherburne, J.A. \& Bissonette, J.A. (1986) Bobcat habitat use and home range size in relation to prey density. The Journal of Wildlife Management, 50, 110-117.

Miquelle, D.G., Goodrich, J.M., Smirnov, E.N., Stephens, P.A., Zaumyslova, O.Y., Chapron, G. et al. (2010) The Amur Tiger: A Case Study of Living on the Edge. Oxford University Press, Oxford, UK.

Orsdol, K.G., Hanby, J.P. \& Bygott, J.D. (1985) Ecological correlates of lion social organization (Panthera leo). Journal of Zoology, 206, 97-112.

Reza, A.H.M.A., Feeroz, M.M. \& Islam, M.A. (2002) Prey species density of Bengal tiger in the Sundarbans. Journal of the Asiatic Society of Bangladesh, Science, 28, 35-42.

Rodgers, A.R. \& CArr, A.P. (1998) HRE: the Home Range Extension for Arc View. User's Manual. Ontario Ministry of Natural Resources, Peterborough, Canada.

SANDELL, M. (1989) The mating tactics and spacing behaviour of solitary carnivores. In Carnivore Behaviour, Ecology and Evolution (ed. J.L. Gittleman), pp. 164-182. Cornell University Press, New York, USA.

SANDERSOn, E.W. (2010) Setting priorities for tiger conservation: 2005-2015. In Tigers of the World: The Science, Politics, and Conservation of Panthera tigris (eds R. Tilson \& P.J. Nyhus), pp. 143-161. Academic Press, San Diego, USA.

Schaller, G.B. (1972) The Serengeti Lion: A Study of Predator-Prey Relations. University of Chicago Press, Chicago, USA.

Seaman, D.E. \& Powell, R.A. (1996) An evaluation of the accuracy of kernel density estimators for home range analysis. Ecology, $77,2075-2085$.

Seidensticker, J. (1976) On the ecological separation between tigers and leopards. Biotropica, 8, 225-234.

Seidensticker, J. (2010) Saving wild tigers: a case study in biodiversity loss and challenges to be met for recovery beyond 2010. Integrative Zoology, 5, 285-299.

Simcharoen, S., Pattanavibool, A., Karanth, K.U., Nichols, J.D. \& Kumar, N.S. (2007) How many tigers Panthera tigris are there in Huai Kha Khaeng Wildlife Sanctuary, Thailand? An estimate using photographic capture-recapture sampling. Oryx, $41,447-453$.
Smith, J.L.D., McDougal, C.W. \& Sunquist, M.E. (1987) Female land tenure system in tigers. In Tigers of the World (eds R.L. Tilson \& U.S. Seal), pp. 97-109. Noyes Publications, Saddle River, USA.

Srikosamatara, S. (1993) Density and biomass of large herbivores and other mammals in a dry tropical forest, western Thailand. Journal of Tropical Ecology, 9, 33-43.

Stephens, P.A., Zaumyslova, O.Yu., Miquelle., D.G., Myslenkov, A.I. \& Hayward, G.D. (2006) Estimating population density from indirect sign: track counts and the FormozovMalyshev-Pereleshin formula. Animal Conservation, 9, 339-348.

Sukmasuang, R. (2001) Ecology of barking deer (Muntiacus spp.) in Huai Kha Khaeng Wildlife Sanctuary. PhD thesis. Kasetsart University, Bangkok, Thailand.

Sunquist, M.E. (1981) The social organization of tigers (Panthera tigris) in Royal Chitwan National Park, Nepal. Smithsonian Contributions to Zoology, 336, 1-98.

Sunquist, M.E., Karanth, K.U. \& Sunquist, F. (1999) Ecology, behaviour and resilience of the tiger and its conservation needs. In Riding the Tiger (eds J.C.S. Seidensticker \& P. Jackson), pp. 5-18. Cambridge University Press, Cambridge, UK.

Thomas, L., Laake, J.L., Strindberg, S., Marques, F.F.C., Buckland, S.T., Borchers, D.L. \& Marques, T.A. (2006) Distance 5.o. Release 2. Research Unit for Wildlife Population Assessment, University of St. Andrews, UK.

Walston, J., Robinson, J.G., Bennett, E.L., Breitenmoser, U. Fonseca, G.A.B., Goodrich, J. et al. (2010) Bringing the tiger back from the brink-the six percent solution. PLoS Biology, 8 , e1000485.

Ward, R.M.P. \& Krebs, C.J. (1985) Behavioural response of lynx to declining snowshoe hare abundance. Canadian Journal of Zoology, $63,2817-2824$.

WeFCOM (Western Forest Complex) (2004) GIS Database and its Applications for Ecosystem Management. The Western Forest Complex Ecosystem Management Project, Department of National Park, Wildlife, and Plant Conservation, Bangkok, Thailand.

Wegge, P., Odden, M., Pokharel, Pd.C. \& Storaas, T. (2009) Predator-prey relationships and responses of ungulates and their predators to the establishment of protected areas: a case study of tigers, leopards and their prey in Bardia National Park, Nepal. Biological Conservation, 142, 189-202.

White, G.C. \& Garrott, R.A. (1990). Analysis of Wildlife Radio Tracking Data. Academic Press, San Diego, USA.

Wikramanayake, E.D., Dinerstein, E., Robinson, J.G., Karanth, U., Rabinowitz, A., Olson, D. et al. (1998) An ecology-based method for defining priorities for large mammal conservation: the tiger as case study. Conservation Biology, $12,865-878$.

\section{Biographical sketches}

Achara Simcharoen specializes in tiger ecology and tiger movement behaviour. Tommaso SAvini's research includes the behavioural ecology of primates and pheasants. GeOrGE A. Gale conducts research on the ecology and population dynamics of birds and mammals. SAKSIT SIMCHAROEN studies the ecology and habitat use of tigers and leopards. SOMPHOT DUANGCHANTRASIRI is in charge of tiger monitoring in the Western Forest Complex of Thailand. SOMPORN PAKPIEN undertakes research on tigers and their prey. James L. D. S Sith investigates landscape-scale tiger ecology. 